\title{
On the electrical double layer capacitance of mesoporous templated carbons
}

\author{
T.A. Centeno $^{a}$, M. Sevilla ${ }^{a}$, A.B. Fuertes ${ }^{a}$, F. Stoeckli* ${ }^{b}$ \\ ${ }^{a}$ Instituto Nacional del Carbón-CSIC. Apartado 73, E-33080 Oviedo (Spain) \\ ${ }^{b}$ Institut de Chimie de l’Université, Av. de Bellevaux 51, CH-2000 Neuchâtel, Switzerland
}

Keywords: A. Porous carbons, electrodes; D. Electrochemical properties, immersion calorimetry.

\section{*Corresponding author. Tel.: + 41-32-7182400 \\ E-mail address: fritz.stoeckli@unine.ch}

In view of their electrical double layer capacitance which can be as high as 150 to $200 \mathrm{~F} \mathrm{~g}^{-1}$, templated carbons have received much attention in recent years, e.g. ref. [1-4]. Their electrochemical performances may be compared with those of classical activated carbons, but the high production costs are a major obstacle to their commercial use. On the other hand, a better understanding of the performances of templated carbons may also provide an insight into the role of mesoporosity in supercapacitors based on activated carbons. The latter, depending on their preparation and the subsequent treatment, may possess a relatively important mesoporosity [5].

The aim of the present study is to show that the electrical double-layer capacitance (EDLC) of the mesoporous surface (pores wider than $2 \mathrm{~nm}$ ) is practically the same as that observed for non-porous carbons. This approach should allow, later, a study of the specific contribution of 
microporosity to the EDLC. Since the approach based on $\mathrm{S}_{\mathrm{BET}}$ can be misleading, in particular for microporous carbons, special care was taken in the structural characterization. Therefore, different and converging techniques were used to determine the surface areas, such as comparison plots, immersion calorimetry and DFT. This leads to specific capacitances in aqueoeus $\mathrm{H}_{2} \mathrm{SO}_{4}$ and $\mathrm{KOH}$ solutions close to the value of 0.130 to $0.150 \mathrm{~F} \mathrm{~m}^{-2}$ reported for non-porous carbons (graphite, graphitized carbon black, glassy carbons) [7-8].

This study is based on six templated mesoporous carbons (C-25-HT, C-50-HT, C-50-90HT, C-50-100-HT, C-50-120-HT and C-50-3/7-HT). For comparison purposes, a commercial graphite (HSAG300) was also examined under the same experimental condition. The synthesis of the templated carbons has been reported elsewhere [4]. Basically, it was performed by impregnating different HMS silica samples with furfuryl alcohol or a 30:70 mixture with trimethylbenzene, followed by carbonization under nitrogen at $800^{\circ} \mathrm{C}$.

The porous structure of the carbons was analysed by $\mathrm{N}_{2}$ adsorption at $-195^{\circ} \mathrm{C}$ (Micromeritics ASAP 2010) and by immersion calorimetry into benzene and $0.4 \mathrm{M}$ phenol aqueous solutions at $20^{\circ} \mathrm{C}[6]$.

The electrical double layer capacitance was determined in two-electrode capacitors by galvanostatic charge-discharge voltage cycles from 0 to $0.8 \mathrm{~V}$ at a current density of $1 \mathrm{~mA}$ $\mathrm{cm}^{-2}$ (potentiostat-galvanostat Autolab-Ecochimie PGSTAT 30). The electrodes (8 $\mathrm{mm}$ in diameter) were made of a mixture of carbon ( $70 \mathrm{wt} \%$ ), polyvinylidene fluoride ( $25 \mathrm{wt} \%)$ binder and carbon black (Super P, $5 \mathrm{wt} \%$ ). They were separated by glassy fibrous paper and placed inside a Swagelok-cell. The electrolytes were aqueous solutions of $\mathrm{H}_{2} \mathrm{SO}_{4}(2 \mathrm{M})$ and $\mathrm{KOH}(6 \mathrm{M})$. The two-electrode configuration provides information corresponding to the superposition of the behaviour of the carbon as cathode and anode but, on the other hand, it is the most reliable technique to know the performance of the carbon in a real capacitor. 
In a first step, the absence of microporosity in the templated carbons was confirmed by the analysis of the low pressure data with the help of Dubinin's eqn $[5,6,9,10]$

$$
\mathrm{N}_{\mathrm{a}}=\mathrm{N}_{\mathrm{ao}} \exp \left[-\left(\mathrm{A} / \beta \mathrm{E}_{\mathrm{o}}\right)^{2}\right]
$$

$A=R T \ln \left(p_{0} / p\right), \beta$ is the affinity coefficient of the adsorptive $\left(0.33\right.$ for $\left.N_{2}\right), E_{o}$ is the characteristic energy, $\mathrm{N}_{\mathrm{a}}$ (usually in $\mathrm{mmol} \mathrm{g}^{-1}$ ) is the amount adsorbed at temperature $\mathrm{T}$ and relative pressure $\mathrm{p} / \mathrm{p}_{\mathrm{o}}$, and $\mathrm{N}_{\mathrm{ao}}$ is the total amount adsorbed. $\mathrm{N}_{\mathrm{ao}}$ corresponds either to the total micropore volume, or the monolayer capacity of the surface of non-porous solids. However, the latter is not always reliable.

As shown elsewhere [9,10] and confirmed by modelling [11,12], for carbons with slitshaped micropores, widths $0.5<\mathrm{L}_{\mathrm{o}}<1.6 \mathrm{~nm}$ correspond to $\mathrm{E}_{\mathrm{o}}$ between $30 \mathrm{~kJ} \mathrm{~mol}^{-1}$ and $18 \mathrm{~kJ}$ $\mathrm{mol}^{-1}$. On the other hand, values below $16 \mathrm{~kJ} \mathrm{~mol}^{-1}$ exclude the presence of classical micropores. This is the case for the carbons of Table 1, C-50-120-HT being a limiting case, and for Vulcan $3 \mathrm{G}\left(\mathrm{E}_{\mathrm{o}}=13.7 \mathrm{~kJ} \mathrm{~mol}^{-1}\right)$, the non-porous reference suggested by Rouquérol et al. [13]. Moreover, the absence of a hysteresis loop for all carbons, except C-50-120-HT and C-50-3/7-HT, suggests the presence of narrow mesopores in a dimension range, which may be defined as sub-Kelvin mesopores (capillary condensation occurs for an equivalent radius larger than 1.7 to $1.8 \mathrm{~nm}[14])$. As confirmed by high resolution electron microscopy, our templated carbons have cylindrical mesopores.

The nitrogen isotherms $(77 \mathrm{~K})$ were analyzed by a comparison plot based on the reference nitrogen isotherm for Vulcan 3G, which has a specific surface area of $81 \mathrm{~m}^{2} \mathrm{~g}^{-1}$ [13]. Typical examples are shown in Figs. 1-2 (carbons C-25-HT and C-50-120-HT). This technique was introduced some years ago by Sing [14]. Later, Kaneko [15] and Setoyama [16] suggested that the initial linear section of the plot reflects the total surface area of the solid under 
investigation. The final linear section corresponds to the external surface area $S_{e}$ and its extrapolation leads to the total pore volume $\mathrm{V}_{\mathrm{p}}$ of the carbon (micro and/or mesopores). Carbon C-50-120-HT, with $\mathrm{E}_{\mathrm{o}}=16.9 \mathrm{~kJ} \mathrm{~mol}^{-1}$ is a limiting case, since the early deviation from linearity indicates the presence of some microporosity. On the other hand, as illustrated by carbon C-25-HT (Fig. 1), for the other carbons the deviation begins only at a relative pressure $\mathrm{p} / \mathrm{p}_{\mathrm{s}}$ near $0.07-0.1$, which corresponds to sub-Kelvin mesopores.

The comparison plots lead to total surface areas $S_{\text {comp }}$ (see Table 1) in the range of 1100 to $1550 \mathrm{~m}^{2} \mathrm{~g}^{-1}$, in good agreement with the values obtained from immersion calorimetry into aqueous solutions of phenol $\left(\mathrm{S}_{\text {phenol }}\right)$ and into benzene $\left(\mathrm{S}_{\text {benzene }}\right)[6]$. These values are also in agreement with $\mathrm{S}_{\mathrm{DFT}}$ (Micromeritics ASAP 2010 software package), assuming cylindrical pores. On the other hand, it appears that in some cases $\mathrm{S}_{\mathrm{BET}}$ overrates the surface area of the carbons. As a first and good approximation, one may therefore use the average total surface area $\mathrm{S}_{\text {average }}=\left(\mathrm{S}_{\text {comp }}+\mathrm{S}_{\text {phenol }}+\mathrm{S}_{\text {benzene }}+\mathrm{S}_{\mathrm{DFT}}\right) / 4$

As shown in Table $1, S_{\text {average }}$ leads to a specific double layer capacitance $C_{o}$ at low current density $\left(1 \mathrm{~mA} \mathrm{~cm}^{-2}\right)$ around 0.125 to $0.145 \mathrm{~F} \mathrm{~m}^{-2}$ for $\mathrm{H}_{2} \mathrm{SO}_{4}$. These values are in good agreement with our own data for the HSAAG300 graphite, and with data reported in the literature [7,8]. For example, Beck and Dolta [8] report values between 0.133 and $0.159 \mathrm{~F} \mathrm{~m}^{-2}$ for high surface area carbon blacks, using $12 \mathrm{M} \mathrm{H}_{2} \mathrm{SO}_{4}$ as electrolyte. One may therefore assume that the specific capacitance of mesoporous carbons for $\mathrm{H}_{2} \mathrm{SO}_{4}$ solutions is close to $0.140 \mathrm{~F} \mathrm{~m}^{-2}$. Similar results are obtained for $6 \mathrm{M} \mathrm{KOH}$, where the average value for $\mathrm{C}_{\mathrm{o}}$ is around $0.120 \mathrm{~F} \mathrm{~m}^{-2}$ and somewhat smaller than for $2 \mathrm{M} \mathrm{H}_{2} \mathrm{SO}_{4}$. Carbon C-50-100-HT, which contains some microporosity, is a limiting case, as preliminary results suggest higher contributions to the EDLC from the internal surface of predominantly microporous carbons [17]. 
It is also interesting to note that for the carbons of Table $1, \mathrm{C}_{\mathrm{o}}\left[\mathrm{F} \mathrm{g}^{-1}\right]$ and $-\Delta_{\mathrm{i}} \mathrm{H}\left(\mathrm{C}_{6} \mathrm{H}_{6}\right)\left[\mathrm{J} \mathrm{g}^{-1}\right]$ are proportional (the ratio $\mathrm{C}_{\mathrm{o}} /-\Delta_{\mathrm{i}} \mathrm{H}\left(\mathrm{C}_{6} \mathrm{H}_{6}\right)$ is near 1.0 for $2 \mathrm{M} \mathrm{H}_{2} \mathrm{SO}_{4}$ and $6 \mathrm{M} \mathrm{KOH}$. This is not too surprising since both quantities are surface properties of the materials. A similar correlation has also been observed for microporous carbons [17] and it will be investigated in more detail.

\section{Conclusions}

The present study suggests that exclusively mesoporous templated carbons, like non-porous carbons, contribute to the double layer capacity $\mathrm{C}_{\mathrm{o}}$ through the extent of their surface area with average values around $0.140 \mathrm{~F} \mathrm{~m}^{-2}$ and $0.120 \mathrm{~F} \mathrm{~m}^{-2}$ for $2 \mathrm{M} \mathrm{H}_{2} \mathrm{SO}_{4}$ and $6 \mathrm{M} \mathrm{KOH}$ solutions, respectively. By extension, in the case of activated carbons this should also apply to the contribution from mesoporosity and from the external surface area $S_{e}$ to the overall capacitance $\mathrm{C}_{0}$. However, as suggested by preliminary investigations, one may expect a more complex contribution from the micropores to the capacitance of templated carbons.

In all cases, the determination of the real surface area remains an important issue and it appears that it should not be limited to $\mathrm{S}_{\mathrm{BET}}$ alone, as it may lead to a wrong conclusions. The combination of independent techniques is advisable.

\section{Acknowledgements}

The financial support provided by the Spanish MCyT (MAT2002-00059) is gratefully acknowledged 


\section{References}

[1] Frackowiak E, Béguin F. Carbon materials for the electrochemical storage of energy in capacitors. Carbon 2001; 39: 937-950.

[2] Vix-Guterl C, Frackowiak E, Jurewicz K, Friebe M, Parmentier J, Béguin F. Electrochemical energy storage in ordered porous carbon materials. Carbon $2005 ; 43$ : 1293 1302.

[3] Barbieri O, Hahn M, Herzog A, Koetz R. Capacitance limits of high surface area activated carbons for double layer capacitors . Carbon 2005; 43: 1303-1310.

[4] Sevilla M, Álvarez S, Fuertes A.B. Synthesis and characterization of mesoporous carbons of large textural porosity and tunable pore size by templating mesostructured HMS silica materials. Micropor. Mesopor. Mater. 2004; 74: 49-58

[5] Bansal RC, Donnet JB, Stoeckli F. In: Active Carbon. New York: Marcel Dekker; 1988. p. 1-14, p. 119-162.

[6] Stoeckli F, Centeno TA. On the determination of surface areas in activated carbons. Carbon 2005; 43: 1184-1190.

[7] Kinoshita K. Carbon Electrochemical and Physicochemical Properties. New York: John Wiley; 1988. pp 293-295.

[8] Beck F, Dolta M. Fluorine-free binders for carbon black based electrochemical supercapacitors. J. Appl. Electrochem. 2001; 31: 517-521.

[9] Stoeckli F. In: Patrick J, editor. Porosity in carbons-characterization and applications. London: Arnold; 1995. p. 67-97.

[10] Stoeckli F. Dubinin's theory and its contribution to adsorption science. Russian Chem. Bull. Int. Ed. 2001; 50: 2265-2270.

[11] Stoeckli F, Guillot A, Slasli AM, Hugi-Cleary D. Microporosity in carbon blacks. Carbon 2002; 38: 211-225. 
[12] Stoeckli F, Guillot A, Slasli AM, Hugi-Cleary D. The comparison of experimental and calculated pore size distributions in activated carbons. Carbon 2002; 38: 383-388.

[13] Rouquérol F, Luciani L, Llewellyn Ph, Denoyel R, Rouquérol J. In : Traité d'Analyse et Caractérisation-Texture des matériaux pulvérulents. Paris: Editions Techniques de l’Ingénieur; 2004. p 1-24.

[14] Gregg SJ, Sing KSW. Adsorption, Surface Area and Porosity. New York: Academic Press; 1982. pp 94-105.

[15] Kaneko K, Ishii C, Ruike M, Kuwabara H. Origin of superhigh surface area and microcrystalline graphitic structures of activated carbons. Carbon 1992; 30: 1075-1088.

[16] Setoyama N, Suzuki T, Kaneko K. Simulation study of the relationship between a highresolution $\alpha_{\mathrm{s}}$-plot and the pore size distribution for activated carbons. Carbon 1998; 36: 14591467.

[17] Centeno, T.A., Stoeckli F. On the specific double layer capacitance of activated carbons, in relation to their structural and chemical properties. J. Power Sourc. (in press) 
Figure 1. $\mathrm{N}_{2}$ comparison plot for C-25-HT, the reference being Vulcan 3G [13]. The arrow indicates the beginning of the mesopore filling.

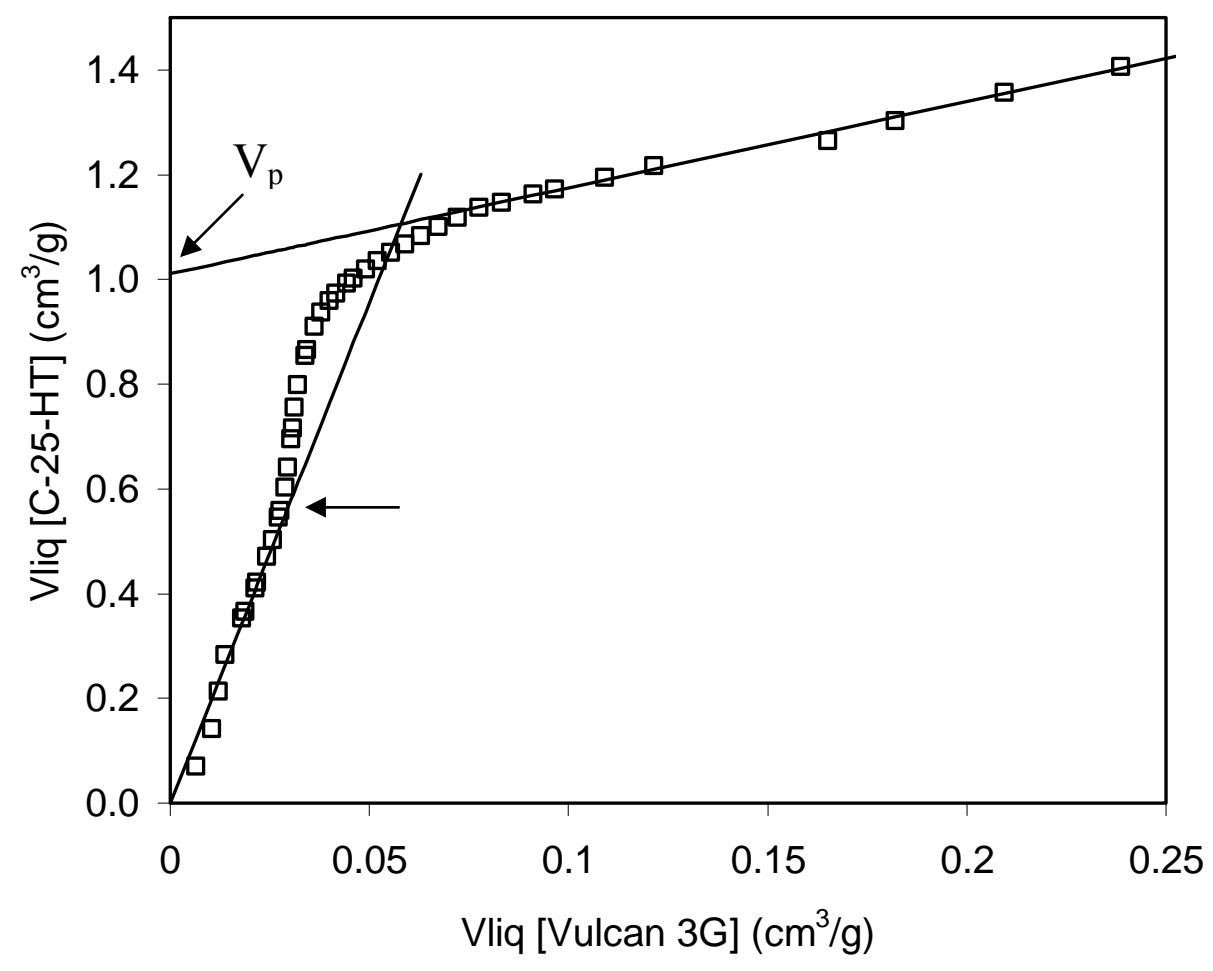


Figure 2. $\mathrm{N}_{2}$ comparison plot for C-50-120-HT, the reference being Vulcan $3 \mathrm{G}$ [13]. The plot suggests the presence of some microporosity, followed by important mesoporosity.

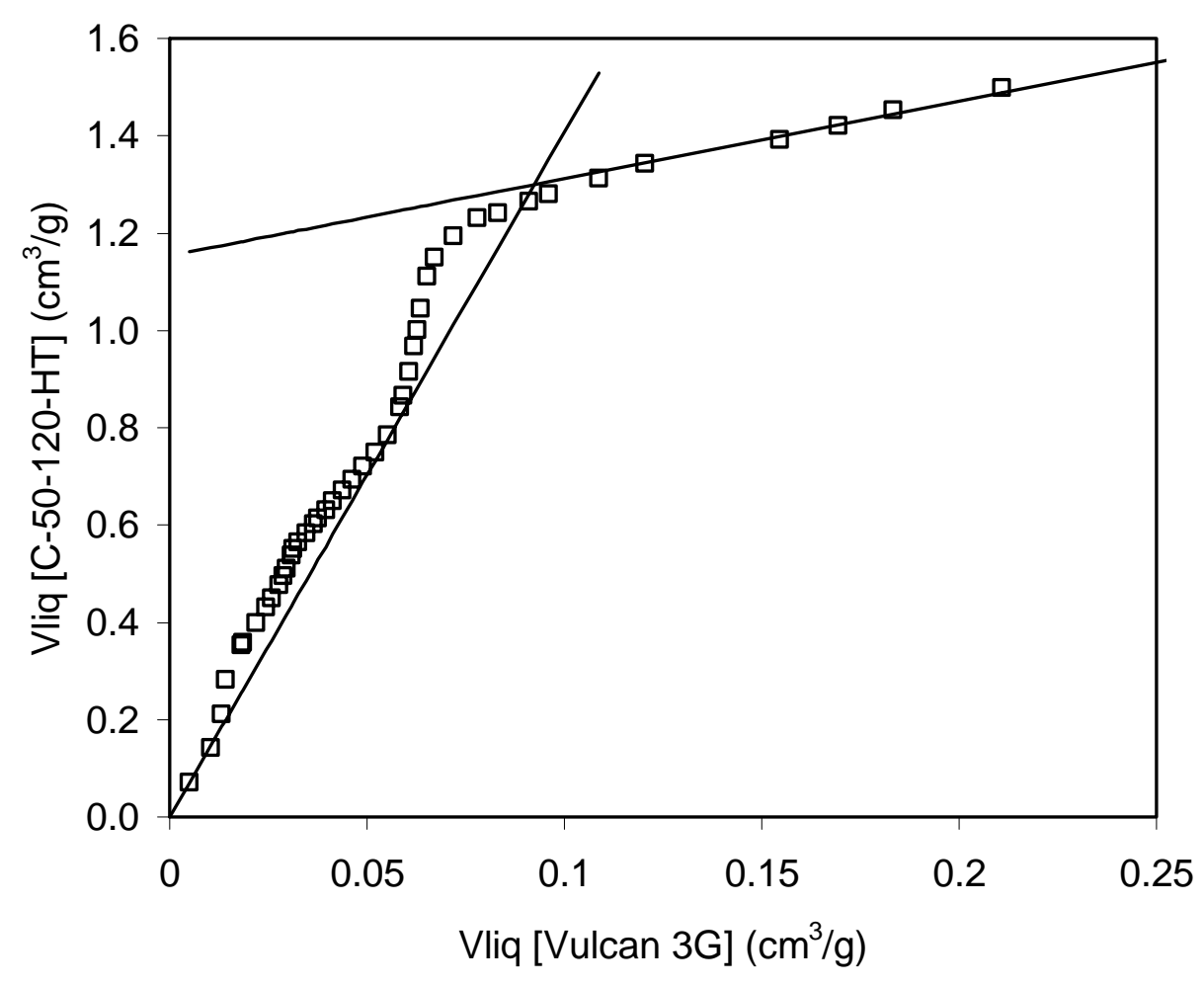


Table 1.Main characteristics of the reference and the templated carbons

\begin{tabular}{lccccccccccccc}
\hline Carbon & $\begin{array}{c}\mathrm{E}_{\mathrm{o}} \\
\left(\mathrm{kJ} \mathrm{mol}^{-1}\right)\end{array}$ & $\begin{array}{c}\mathrm{V}_{\mathrm{p}} \\
\left(\mathrm{cm}^{3} \mathrm{~g}^{-1}\right)\end{array}$ & $\begin{array}{c}\mathrm{S}_{\mathrm{BET}} \\
\left(\mathrm{m}^{2} \mathrm{~g}^{-1}\right)\end{array}$ & $\begin{array}{c}\mathrm{S}_{\mathrm{DFT}} \\
\left(\mathrm{m}^{2} \mathrm{~g}^{-1}\right)\end{array}$ & $\begin{array}{c}\mathrm{S}_{\mathrm{comp}} \\
\left(\mathrm{m}^{2} \mathrm{~g}^{-1}\right)\end{array}$ & $\begin{array}{c}\mathrm{S}_{\text {phenol }} \\
\left(\mathrm{m}^{2} \mathrm{~g}^{-1}\right)\end{array}$ & $\begin{array}{c}\mathrm{S}_{\text {benzene }} \\
\left(\mathrm{m}^{2} \mathrm{~g}^{-1}\right)\end{array}$ & $\begin{array}{c}\left.-\Delta_{\mathrm{i}} \mathrm{H}_{\mathrm{C}} \mathrm{H}_{6}\right] \\
\left(\mathrm{Jg}^{-1}\right)\end{array}$ & $\begin{array}{c}\mathrm{C}_{\mathrm{o}} \\
{\left[\mathrm{H}_{2} \mathrm{SO}_{4}\right]} \\
\left(\mathrm{Fg}^{-1}\right)\end{array}$ & $\begin{array}{c}\mathrm{C}_{\mathrm{o}}{ }^{*} \\
{\left[\mathrm{H}_{2} \mathrm{SO}_{4}\right]} \\
\left(\mathrm{Fm}^{-2}\right)\end{array}$ & $\begin{array}{c}\mathrm{C}_{\mathrm{o}} \\
{[\mathrm{KOH}]} \\
\left(\mathrm{Fg}^{-1}\right)\end{array}$ & $\begin{array}{c}\mathrm{C}_{\mathrm{o}}^{*} \\
{[\mathrm{KOH}]} \\
\left(\mathrm{Fm}^{-2}\right)\end{array}$ \\
\hline HSAG300 & 16.4 & 0.33 & 340 & - & 315 & 331 & 329 & 37.6 & 47 & 0.144 & - & - \\
C-50-90-HT & 13.6 & 1.15 & 1496 & 1415 & 1240 & 1330 & 1119 & 127.6 & 184 & 0.144 & 158 & 0.124 \\
C-25-HT & 13.7 & 1.01 & 2250 & 1252 & 1546 & 1102 & 1333 & 152.0 & 161 & 0.123 & 162 & 0.124 \\
C-50-3/7-HT & 14.2 & 1.39 & 2060 & 1267 & 1387 & - & 1514 & 172.6 & 187 & 0.129 & - & - \\
C-50-HT & 14.9 & 1.07 & 2352 & 1132 & 1124 & 1076 & 1492 & 170.1 & 172 & 0.140 & 138 & 0.114 \\
C-50-100-HT & 16.7 & 1.20 & 1410 & 1384 & 1114 & 1266 & 1072 & 122.2 & 163 & 0.137 & 145 & 0.120 \\
C-50-120-HT & 16.9 & 1.15 & 1330 & 1369 & 1138 & 1330 & 1098 & 125.2 & 159 & 0.129 & 150 & 0.122
\end{tabular}

*Using $\mathrm{S}_{\text {average }}=\left(\mathrm{S}_{\text {comp }}+\mathrm{S}_{\text {phenol }}+\mathrm{S}_{\text {benzene }}+\mathrm{S}_{\mathrm{DFT}}\right) / 4$ 